\title{
The psychiatric careers of male shelter users in Nottingham
}

\author{
Leena Roy, Consultant Psychiatrist, Park Prewett Hospital, Aldermaston Road, \\ Basingstoke RG24 9LZ; and SUE READ, Senior Research Officer, Department of \\ Public Health, Leicestershire Health Authority
}

Descriptions of psychiatric morbidity among the homeless have generally been carried out in community settings (Marshall, 1990) or among those who have come into contact with psychiatric services.

In the latter group most studies (Priest, 1976; Berry \& Orwin, 1966; Herzberg, 1987; Hamid \& McCarthy, 1989) have shown high rates of psychiatric morbidity, especially of schizophrenia, personality disorder, and alcoholism. Many of those admitted to hospital came by way of the Police and Accident and Emergency Departments. A large proportion discharged themselves against advice, and for those who stayed, rehabilitation and rehousing were very difficult to achieve.

\section{The study}

This study describes the past use of psychiatric services made by a sample of local shelter users in Nottingham. Three local services for the homeless, the Salvation Army, the Night Shelter, and Elm House, agreed to keep a record of all men using their beds over a six week period in 1987. Their ages and lengths of stay in the shelters were also noted. The number of women in these shelters was extremely small, and they were excluded from this study.

The Nottingham psychiatric case register was used to identify which of these men had made contact with the local psychiatric services and their case-notes were traced. Information was extracted from these on socio-demographic characteristics, mode of first presentation to psychiatric services, diagnoses (ICD9), and the nature of care received. The type of follow-up arranged and the nature of accommodation at last contact with the psychiatric services were also noted where available.

\section{Findings}

During the study period 299 men used the three shelters, of whom $82(27 \%)$ had made at least one contact with the local psychiatric services. Despite extensive efforts the case-notes of one man were not traceable, and he was excluded from the study. Two men who had been referred never made contact. Information from their referral letters was included as appropriate. Men who had had contact with psychiatric services were significantly older than those who had not made contact but who were living in the shelters $\left(\chi^{2}=30.7\right.$, degrees of freedom $\left.=4, P 0<.001\right)$.

Only $30(37 \%)$ of the psychiatric contact group had ever been married. Social class could only be coded for 58 men, of whom two thirds had held their best jobs within a manual class. The proportions of men in each shelter were similar to those who had not had any psychiatric contact, with two thirds of the men in both groups staying at the Salvation Army, reflecting its size. Men who had had psychiatric contact were significantly more likely to have been using shelters for longer (months rather than weeks).

The highest proportion of first referrals to the psychiatric services was from general practitioners (38, $43 \%$ ). Seven referrals came from accident and emergency services (A \& E), 16 from prison doctors, probation officers, the police and courts. Four of the men first presented as front door self-referrals, three through staff at the shelters, and a further four from social services. However, later in their psychiatric careers a further six presented as self-referrals by the front door. Eight were re-referred by the A \& E services, and ten re-referred by the police, probation, courts and prisons. A majority $(50,62 \%)$ had a forensic history.

Twenty-seven men $(33 \%)$ were assessed once only, of whom four were seen as out-patients, five in the shelters by staff of the alcohol services, six for legal reports, and six by the liaison service. Over half of these were alcoholics and drug abusers, with only two having psychotic illnesses.

The majority of other referrals resulted in admission (35, 64\%), 13 being admitted for detoxification from alcohol, and 13 with a diagnosis of schizophrenia. The number of admissions per person ranged from 1 to 21 (mode $=1$, mean $=3.8$ ). Six men had been in-patients for more than a year, two for more than five years. However, the majority had been in-patients for weeks or months. Twenty-four men had been in-patients in psychiatric hospitals outside the area. 
TABLE I

Diagnoses of men who had been in contact with psychiatric services

\begin{tabular}{lccc}
\hline & $\begin{array}{c}\text { Primary } \\
\text { diagnosis }\end{array}$ & $\begin{array}{c}\text { Second } \\
\text { diagnosis }\end{array}$ & $\begin{array}{c}\text { Third } \\
\text { diagnosis }\end{array}$ \\
\hline Alcohol abuse/dependence & 30 & 3 & 3 \\
Schizophrenia & 19 & 4 & 1 \\
Affective disorder & 3 & 2 & 1 \\
Neurotic disorder & 14 & 14 & 5 \\
Personality disorder & 4 & 8 & 1 \\
Low intelligence/mental handicap & 4 & 1 & \\
Organic brain disorder & 1 & 3 & 1 \\
Drug dependence/abuse & 2 & 1 & \\
Psychoses-other & 1 & 2 & \\
Deliberate self-harm & 2 & & \\
Sexual deviation & - & - & \\
Epilepsy & 81 & 38 & 11 \\
No psychiatric diagnosis & 1 & & \\
\hline
\end{tabular}

The diagnoses given for those in contact with psychiatric services are shown in Table I. The most common main diagnosis was alcoholism $(37 \%)$. Almost half of the men received two or more diagnoses. Those admitted were significantly more likely to have a diagnosis of schizophrenia or alcoholism $\left(\chi^{2}=20.4, \mathrm{df}=3, P<0.0001\right)$. Six men with major mental illness had been admitted directly from the shelters, a further seven men for detoxification from alcohol.

At the time of first contact with the psychiatric services, $17(20 \%)$ men were in the shelters (6 with alcoholism, 3 with schizophrenia). At the time of last contact with the services the number of men within the shelters had doubled to $36(44 \%)$ (13 with alcoholism and 11 with schizophrenia).

Arrangements for psychiatric follow-up were made for 41 , mostly as out-patients, or with social workers or community psychiatric nursing services. However, two-thirds $(28,68 \%)$ of those for whom follow-up was organised lost contact with the service, and only 12 were still in contact with the service six months after the study period. Patients with alcohol problems were significantly more likely to have been lost to contact, and those with a diagnosis of schizophrenia to still be in contact $(P<0.0004)$.

\section{Comments}

This study looked at all psychiatric contacts made by a cohort of shelter users with the local psychiatric services. The study was only possible because the case register was used to record every contact with psychiatric services, and to link events to people. Over a quarter of the men using the local shelters had made at least one contact with the local psychiatric service. Although many were seen only once, half received in-patient care and many had used psychiatric services elsewhere. Clearly there is a high psychiatric morbidity among this population.

Studies that have looked at no fixed abode admissions have found high rates of referral from the police and casualty services. Perhaps because we looked at all psychiatric contacts and not just admissions, we found that GPs made the largest proportion of first referrals to the service, although a substantial number of referrals and re-referrals came from casualty and police services.

The difficulties of following up this heterogeneous population were again highlighted by the small numbers who were still in contact with services. There seemed to be two major groups, those with alcoholism and personality disorders (often combined), and those with major mental illness frequently combined with other significant diagnoses. The former group often made repeated brief contacts, losing touch with services in between. The outcome for those with major mental illnesses was more varied. Only a third were still in contact with the service, most of whom were on medication. Over a half of this group were in the shelters at last recorded contact, the vast majority having lived there for over a year. In only a few cases had attempts been made to offer alternative accommodation, and some of these had failed because of the individuals' behaviour. The number of men living in the shelters had doubled between first and last psychiatric contacts, and was most obvious for those with schizophrenia. There was a small core of men with mild mental handicap who had been in-patients in mental handicap 
hospitals for years. On leaving these institutions they had resorted to a life of petty crime and had also drifted to the shelters.

With the College highlighting the need for discharge and after-care plans, and the Department of Health's Care Programme approach, there will perhaps be better recording of discharge plans in notes. The responsibility for coordinating and delivering the service to those discharged from hospital and from psychiatric care will also be clearer. While this may improve the care given to future referrals to the psychiatric services, there remains a reservoir of people who have 'fallen through the net' and their needs have yet to be addressed. However, delivering a service to this group of mentally ill people remains difficult as these individuals seem to have other major difficulties apart from their severe mental illnesses. Perhaps for many it is the combination of a severe mental illness, with personality difficulties or low intelligence, that leads to social isolation, lack of support, rejection of services provided, and a drift into substandard accommodation and criminality.

\section{References}

BerRy, C. \& OrWIN, A. (1966) No fixed abode. A survey of mental hospital admissions. British Journal of Psychiatry. 12, 1019-1025.

HAMID, W. A. \& MCCARTHY, M. (1989) Community psychiatric care for homeless people in inner London. Health Trends, 21, 67-69.

Herzberg, J. L. (1987) No fixed abode: a comparison of men and women admitted to an East London psychiatric hospital. British Journal of Psychiatry, 150, 621-627.

Marshall, M. (1989) Collected and neglected: Are Oxford hostels for the homeless filling up with disabled psychiatric patients? British Medical Journal, 299, 706-709.

Priest, R. G. (1976) The homeless person and the psychiatric services: an Edinburgh survey. British Journal of Psychiatry, 128, 128-136.

\title{
The relationship between hospital hostels in the community and the general practitioners who look after them
}

\author{
DANNy Allen, Senior Registrar, Barrow Gurney, Bristol BS19 3SG
}

As long-stay patients move into the community, the relationship with the psychiatrist gets diluted. One reason is the logistical problem of visiting widely spaced residences, but another is that patients are primarily under the care of general practitioners (GPs) who provide physical care in the majority of cases. The way in which psychiatric care is delivered is variable (Horder, 1991). For the system to function a modus vivendi has to develop between GPs, psychiatrists and care staff. This study looks at current practice in Gloucester.

\section{The study}

The Gloucester model of community care has been written about elsewhere (Anstee, 1985; 1991). The study looked at the core of the system: four 'hospitalhostels' and a rehabilitation hostel with a total population of 34. Questionnaires were sent to all hostel staff asking for their views about GPs' practices and psychiatrists and about the number of contacts GPs had had with residents, and to GPs asking for their views of the hostels.

\section{Findings}

\section{Staff}

The five GPs qualified between 1960 and 1979. There were three clinical assistants, one in psychiatry and two in mental handicap. They had looked after homes/hostels for between one and ten years. Sixtyfive questionnaires were given out to hostel staff and $37(57 \%)$ were returned. Staff had been working in hostels between 3 weeks and $7 \frac{1}{2}$ years. There were 13 registered mental nurses, 13 nursing auxiliaries, 7 state enrolled nurses and 4 students.

\section{General practitioners' views}

All five GPs approved of hostels as a way of looking after this particular group of people. They said that carers almost always accompanied residents to the surgery and they thought it useful that they did 